\title{
Pesticides in agriculture: are we sustainable yet?
}

\author{
József Kiss ${ }^{1}$
}

Received: 30 July 2019/Accepted: 31 July 2019/Published online: 7 August 2019

(C) Bundesamt für Verbraucherschutz und Lebensmittelsicherheit (BVL) 2019

\begin{abstract}
About 10 years ago, the EU published a framework for community action to achieve a sustainable use of pesticides, aiming to reduce the risks and impacts of pesticide use on human health and the environment. ${ }^{1}$ Furthermore, it implies the promotion of Integrated Pest Management (IPM) and non-chemical alternatives to pesticides. The directive defines actions and areas of implementation, such as training, requirements for pesticide sales, pesticide application equipment, public information, specific measures to protect the aquatic environment and drinking water, reducing pesticide use, and so on. The Member States had to elaborate a National Action Plan (NAP) by 2012 and implement it in their agricultural practice latest by January 2014 .
\end{abstract}

In 2017, a report by the Commission assessed the implementation of the NAP and the Directive in each Member State. ${ }^{2}$ There was a progress in training and certificates, pesticide application equipment, reduction of aerial spraying. However, also inconsistencies and a lack of quantitative objectives and measurable targets. The Report was discussed by the Committee on the Environment, Public Health and Food Safety of the European Parliament in early 2019 with conclusions, and recommendations. ${ }^{3}$

Detailed cross-cutting considerations and important non-technical (socio-economic) aspects are needed for the successful implementation of the Directive. This article aims to highlight important aspects that are needed for the further implementation of the Directive.

József Kiss

jozsef.kiss@mkk.szie.hu

1 Plant Protection Institute, Szent István University, Pater K. Street 1, 2100 Gödöllő, Hungary

\section{Taking IPM further}

IPM includes tools and measures to implement the Directive. IPM is based on healthy crop stands and encourages the use of "natural pest control mechanisms", e.g. pest population regulation by predatory arthropods and parasitoids. Farmers are "decision makers" and key actors for the implementation of the Directive without disregarding and neglecting to role of advisors and extension specialists supporting farmers in making appropriate decisions along the implementation process. Farmers are able to enhance natural mechanisms in various ways, for instance by supporting the conservation of biological control mechanisms e.g. by establishing flower strips, field margins, and maintaining semi-natural habitats (SNHs). This may include a 'green payment' to farmers for preserving natural resources with 'Ecological Focus Areas'. ${ }^{4}$ However, farmers need clear instructions on how to preserve natural resources and learn from cases where those areas have already been implemented. Also, these mechanisms can be enforced by the release and application of living organisms, e.g. predators, parasitoids, entomopathogenic fungi, nematodes and antagonists (augmentative biological control) and with that reducing pesticide use with various potentially low-risk active substances that are approved for plant protection, e.g. garlic extract, plant oils, etc. Further registrations of potentially low-risk active substances, natural compounds, and organisms that fit the principle of „supporting natural regulating mechanisms" are needed. Based on recent literature, there is an increased global interest in these solutions that calls for far-reaching steps to implement a biopesticides based solution (Balog et al.

\footnotetext{
${ }^{1}$ https://eur-lex.europa.eu/legal-content/EN/ALL/?uri=celex\%3A32 009L0128. Accessed 25 Jul 2019.

2 https://eur-lex.europa.eu/legal-content/EN/TXT/?uri=COM\%3A20 17\%3A587\%3AFIN. Accessed 30 Jul 2019.

3 http://www.europarl.europa.eu/doceo/document/A-8-2019-0045_ EN.html. Accessed 30 Jul 2019.

${ }^{4}$ https://ec.europa.eu/info/food-farming-fisheries/key-policies/com mon-agricultural-policy/income-support/greening_en. Accessed 30 Jul 2019.
} 
2017). For example, the exemption from fees for the registration of novel pesticides (e.g. biopesticide) fits well with current IPM programmes and the compatibility assessment of pesticides to IPM programme (Farrar et al. 2018).

\section{Systems approach vs. broader systems}

IPM has a long history in the sustainable rural development as a main approach in pest management. Furthermore, integrated crop management (ICM), integrated production (IP) and integrated farming (IF) are well-known global approaches defined by various international organizations. However, they are all systems approaches both for cropping systems and broader farming systems. Farms are financially, technically functional units and agro-ecosystems in our landscapes. They generally consist of non-crop habitats, fields of various crops and associated living organisms (weeds, arthropod assemblages, pathogens, etc.) that are interacting (via trophic chains). One may address a pest problem in a single crop field in a given time period, but there is a clear need for a shift from single crop management towards a broader system. Farmers are expecting easy, ready to use, timely tools and solutions for managing pests in a single crop and a single growing year. A broader approach to substantially decrease pest populations in crops needs convincing tools and an orientation towards spatially and temporally larger scales. The broad spectrum of cropping components (variety, nutrient supply, soil management, rotation, pest management) can only be efficiently addressed on farms. Thus, a promising step forward are system based solutions for farmers that embed cropping systems, support better understanding and acceptance of system operation including farm level expenses and profits. The ongoing effort to implement system operation, initiative and activity on farms as shown by some Member States (e.g. Germany and France) with an established and operating IPM plays an important role. Those farms could also contribute to develop and test risk indicators and conduct risk assessments under realistic exposure (field and farm) scenarios and conditions. Farmers want to decide for their crops cultivated in a cropping system and also for the associated pest management and target profits delivered by the crops. To decide on control and management options, they need clear decision support tools and methods. There is broad range of decision support tools and systems available in Europe. But are they actually used by farmers and advisors? And are those tools and decision support systems available and validated in European farming systems for IPM targets to manage local ecosystems? Assumingly, there is still space for improvement. Those tools for pest management in natural, social, economic, personal farming are largely unrecognized by the users.

The implementation of the Directive with different solutions and gained experiences could strengthen overall European IPM implementation (Lamichhane et al. 2016). Pests do not respect borders and management options. Consequently, the experiences of the entire cropping/farming system derived from various European natural and societal environments need to be shared in Europe. Scientists are more likely to use global regional networking opportunities. Would it be possible to create a sharing environment of knowledge for farming, pest management solutions, and system management for the European Member States? Transnational and cross border activities may cover knowledge from many regions, including management of invasive pests, newly born, accidentally introduced or migrating pests. The former quarantine maize pest, Western Corn Rootworm that spread from central Europe all over the place is a good example for that (Boriani et al. 2006).

\section{The participatory approach}

Farmers are the main "implementers" of rural development policy and their related measures, and with that ensure food and feed safety and satisfy society calls to maintain our ecosystem. In order to broaden the farming aims towards maintaining ecosystem services, farmers should be motivated and allowed to discover appropriate pest management solutions, relevant to their conditions and able to address new challenges. They need to be prepared and supported when dealing with present and future challenges. In Asia, the FAO helped to establish and develop Farmer Field Schools (FFS) that focuses on the resources of poor farmers. After 30 years of activity, the FFS built a successful participatory approach in more than 90 countries, including central Europe. ${ }^{5}$ This is undoubtedly applicable in the EU as well, with adjustments to European conditions. And indeed, key parameters like networking, co-innovation efforts, involving key stakeholders, and including farmers are also proposed by the agricultural European Innovation Partnership (EIP-AGRI). ${ }^{6}$ What we need for the implementation of the IPM as a next step is to extend and apply this approach in down-scaled farming regions with the understanding and support by the Member States.

\footnotetext{
5 http://www.fao.org/webcast/home/en/item/5031/icode/. Accessed 25 Jul 2019.

${ }^{6}$ https://ec.europa.eu/eip/agriculture/en/about. Accessed 25 Jul 2019.
} 


\section{References}

Balog A, Hartel T, Loxdale HD, Wilson K (2017) Differences in the progress of the biopesticide revolution between the EU and other major crop-growing regions. Pest Manag Sci 73:2203-2208. https://doi.org/10.1002/ps.4596

Boriani M, Agosti M, Kiss J, Edwards CR (2006) Sustainable management of the western corn rootworm, Diabrotica virgifera virgifera LeConte (Coleoptera: Chrysomelidae), in infested areas: experiences in Italy, Hungary and the USA. EPPO Bull 36:531-537

Farrar JJ, Ellsworth PC, Sisco R et al (2018) Assessing compatibility of a pesticide in an IPM program. JIPM 9(1):1-6

Lamichhane JR, Aubertot JN, Begg G et al (2016) Networking of integrated pest management: a powerful approach to address common challenges in agriculture. Crop Protect 29:139-151

Publisher's Note Springer Nature remains neutral with regard to jurisdictional claims in published maps and institutional affiliations. 